\title{
A construção do Estado Plurinacional na Bolívia como tentativa de institucionalizar o abigarrado
}

Clayton Mendonça Cunha Filho

Observatório Político Sul-Americano

\begin{abstract}
The objective of this work is to analyze the construction of the Plurinational State as an attempt to provide Bolivia with an institutional framework adequate for its particular reality, starting from its own indigenous models. I begin by examining the concept of abigarrada social formation coined by René Zavaleta to describe the Bolivian society and how that same concept positions itself in relation to Gino Germani's theory of modernization and Dipesh Chakrabarty's theoretical notions in describing the process of expansion from Capitalism in peripheral countries. Immediately following, I discuss the implications of that Bolivian abigarramiento in the construction of the Nation-State and its limitations in the country, after which I examine the proposal for the composition of the Plurinational State and conclude by discussing some of the practical implications that have arisen up to today for the new institutional experiment and its perspectives for consolidating the country.
\end{abstract}

\section{Keywords}

abigarrada society, Bolivia, communal-indianism, national-popular, Plurinational State 


\section{Resumo}

O objetivo deste trabalho é analisar a construção do Estado Plurinacional como tentativa de dotar a Bolívia de uma institucionalidade adequada a sua realidade particular, partindo de modelos próprios e autóctones. Inicio revisando o conceito de formação social abigarrada cunhado por René Zavaleta para descrever a sociedade boliviana e como o mesmo se coloca frente à teoria da modernização de Gino Germani e às noções teóricas de Dipesh Chakrabarty para descrever o processo de expansão do capitalismo nos países periféricos. Em seguida, discuto as implicações desse abigarramento boliviano para a construção do Estado-nação e suas limitações no país, após o quê discuto a proposta de conformação de um Estado Plurinacional e concluo discutindo algumas das implicações práticas trazidas até aqui pelo novo experimento institucional e suas perspectivas de consolidação no país.

\section{Palavras claves}

Bolívia, Estado Plurinacional, indianismo-comunitário, nacional-popular, sociedade abigarrada

Con un modelo de nación que no corresponde con la realidad boliviana, el país aparece como pueblo enfermo o pueblo niño, como fracaso, subdesarrollo, absurdo, inviable; al punto que hoy la élite tradicional ha renunciado completamente a representar esta nación y construye un imaginario de territorio propio, lejos del mundo indígena, del mundo 'colla', en el oriente, y acaba vaciando la representación de la nación que condujo desde la fundación de república.

Ximena Soruco Sologuren

A história política da Bolívia tem sido frequentemente contada como a história de uma modernização fracassada, de um país incapaz de se desenvolver e superar a fragilidade institucional que o destaca como um dos mais instáveis do mundo. ${ }^{1}$ Entretanto, embora recorrente e em grande

\footnotetext{
${ }^{1}$ Desde sua independência em 1825, a Bolívia é caracterizada por grande instabilidade política. De seus 83 governos de lá até a posse de Evo Morales em 2006, "treinta y seis no duraron más de un año, treinta y siete fueron de facto y hasta el momento ningún historiador ha sabido precisar la cantidad exacta de golpes
} 
medida dominante, esse é um relato que peca por tomar como dada a narrativa da história humana como a do avanço paulatino rumo ao "progresso", medido em termos da comparação com a situação dos países mais "avançados".

Embora as teorias que tratavam a modernização como um "processo linear que levaria à transformação das estruturas sociais e econômicas de tradicionais a modernas, entendidas como modernas as formas existentes nas sociedades (ocidentais) de industrialização pioneira" (Avritzer e Costa 719) em uma série de estágios pelos quais todos os países passariam inexoravelmente tenham caído em progressivo descrédito científico na segunda metade do século XX, muitas de suas noções gerais permaneceram implícitas no discurso e nas análises políticas dentro e fora da academia. Desse modo, embora não seja dito de forma explícita na maioria das vezes, países como a Bolívia são analisados a partir do prisma comparativo da expectativa de que um dia ela deveria vir a ser, por exemplo, como a Suíça (para ficar em um país com alguma similitude geográfica) em sua estrutura econômica e seu funcionamento político. Como a Bolívia não é a Suíça, é tratada então como um país fracassado, instável, incapaz.

Entretanto, "se a desordem é tão prevalecente não seria ela a própria ordem? Não poderia haver sistematicidade no caos? Não deveria ela ser entendida menos como interrupção que como continuidade?" (Dunkerley xi). E de fato, a busca por alcançar um "sistema ocidental perfeito" parece ser muito mais quimérica do que a aceitação de que o funcionamento do sistema político, social e econômico local pode se dar de uma maneira sui generis, atendendo talvez a lógicas próprias, sem que por isso deva ser considerado como inferior, fracassado, incompleto ou sequer como não moderno.

Parte dessa lição parece ter sido assimilada após a estrutura de oportunidades políticas, isto é, as "consistentes... dimensões da luta política que encorajam as pessoas a se engajar no confronto político" (Tarrow 1994, 85), aberta pelo turbulento quinquênio 2000-2005, que praticamente liquidou com o regime político vigente e seu sistema de partidos e propiciou uma ampla renovação dos quadros dirigentes do país a partir da eleição à presidência de Evo Morales ao fim do último ano daquele período. A nova dirigência política, ancorada no partido Movimento Ao Socialismo (MAS) e num bloco histórico apoiado em fortes elementos indígenas e nacional-

de Estado e intentonas militares" (Sivak 11). Tal situação de instabilidade crônica levou a mesma a ser comparada a uma "história sem fim" (Guimarães, Domingues e Maneiro).

Bolivian Studies Journal /Revista de Estudios Bolivianos

http://bsj.pitt.edu

Vol. 20 • 2014 • doi: 10.5195/bsj.2014.87 • ISSN 1074-2247 (print) • ISSN 2156-5163 (online) 
populares, tem investido numa retórica de descolonização e refundação do país cujo principal fruto foi a convocação de uma Assembleia Constituinte em 2006 e a promulgação de uma nova constituição em 2009 que extinguiu a então República da Bolívia para dar lugar ao Estado Plurinacional da Bolívia.

Um dos objetivos declarados da mudança, que se pretende mais que uma mera troca de nomenclatura, seria o de ajustar-se consigo mesma, reconhecendo o país realmente existente. Composta por uma imensa diversidade étnica e por povos com laços comunitários ainda bastante presentes e institucionalidades políticas próprias, a Bolívia declara buscar com a plurinacionalidade construir um novo modelo capaz de incorporar efetivamente essa diversidade. Mas até que ponto vem sendo bem-sucedida no intento?

O objetivo deste trabalho é precisamente analisar a construção do Estado Plurinacional como tentativa de dotar o país de uma institucionalidade adequada a sua realidade particular, partindo de modelos próprios e autóctones. Inicio o trabalho revisando o conceito de formação social abigarrada ${ }^{2}$ cunhado por René Zavaleta para descrever a sociedade boliviana e como o mesmo se coloca frente à teoria da modernização desenvolvida por Gino Germani e às noções teóricas desenvolvidas pelo historiador indiano Dipesh Chakrabarty para descrever o processo de expansão do capitalismo nos países periféricos. Em seguida, discuto as implicações desse abigarramento social boliviano para a construção do Estado-nação e suas limitações no país, tais como ao alcance de sua sociedade civil e legitimidade estatal apoiando-me nas teorizações de Chatterjee, Tapias e Neocosmos sobre o tema. Após, discuto a proposta de conformação de um Estado Plurinacional como tentativa de solução institucional do problema e por último, concluo discutindo algumas das implicações práticas trazidas até aqui pelo experimento e suas perspectivas de consolidação.

\section{Sociedade abigarrada e os tempos do capital}

$\mathrm{Na}$ tentativa de compreender e explicar seu país natal, o sociólogo boliviano René Zavaleta cunhou o já célebre conceito de "formação social abigarrada": a sociedade boliviana seria composta, na verdade, por muitas

\footnotetext{
${ }^{2}$ Abigarrado, em espanhol, seria traduzido ao português como variegado, feito de retalhos justapostos. Como a tradução parece perder um pouco do sentido original, opto por manter o termo no original.
} 
sociedades e civilizações justapostas, com tempos socioeconômicos distintos e na qual nenhuma delas é capaz de impor sua hegemonia completamente sobre as outras (ver Tapia 2002; Zavaleta Mercado 2009). Ao mesmo tempo em que possuía setores capitalistas modernos e conectados à economia mundial, como os enclaves mineiros, a Bolívia ostentava comunidades isoladas e com economias de subsistência não capitalista. $O$ encadeamento entre essas várias sociedades e economias seria mínimo, muitas vezes meramente formal e era nessa característica peculiar, cujas origens remontam em grande medida ao legado colonial espanhol, que Zavaleta identificava a origens das frequentes crises de hegemonia pelas quais passava o país.

Apesar da brutalidade da conquista, os espanhóis em grande medida se adaptaram a formas de governo e extração de excedente econômico das civilizações autóctones pré-existentes em vez de buscar reconstruir profundamente a colônia. Em troca do pagamento de tributos e mão de obra para trabalhos nas minas, concederam por muito tempo alto grau de autonomia de facto a diversas comunidades indígenas, utilizando-se de lideranças locais e remanescentes das linhagens de nobreza incaica como intermediários do poder colonial. Durante a colônia, após a consolidação administrativa efetuada pelas ordenanças do vice-rei Francisco de Toledo (1574 e 1577), os caciques indígenas possuíam uma série de prerrogativas análogas às dos nobres espanhóis conquanto respeitassem suas obrigações de vassalagem perante a coroa e executassem seu papel de elo entre a sociedade de peninsulares e crioulos e as comunidades indígenas pelas quais eram responsáveis. Embora sofressem discriminações e nem sempre tivessem seus privilégios respeitados, os caciques indígenas tinham reconhecidos pela coroa espanhola, por exemplo, o direito de "montar a cavalo, portar armas, utilizar escudo equivalente ao escudo nobiliárquico espanhol e não pagar tributos" (ver Mesa, Gisbert e Mesa Gisbert 119-129). Após a independência em 1825, boa parte desse arranjo de coexistência foi mantido, mas com a exclusão formal da cidadania dos indígenas na nascente república, apesar de serem eles a maior parte da população.

A república recém independente do domínio espanhol mantinha-se, no entanto, extremamente dependente do Tributo Indígena ${ }^{3}$ que representava

\footnotetext{
${ }^{3}$ Imposto criado pela coroa espanhola que incidia sobre as comunidades indígenas livres e posteriormente estendido para todos os índios da colônia, sendo que a taxa sobre os servos das haciendas, terras privadas comerciais nas mãos de criollos e espanhóis, deveria ser paga pelo fazendeiro como forma de incentivar a migração voluntária de indígenas para trabalhar nas fazendas.
} 
cerca de $60 \%$ dos recursos arrecadados pelo novo Estado (Klein 105-106). Tal fato condicionou por muito tempo as possibilidades de mudança no regime de coexistência entre a república crioula moderna e as comunidades tradicionais autônomas, com a manutenção dessa autonomia de facto das terras comunais, contribuindo para consolidar a sociedade abigarrada que analisaria Zavaleta.

Isto não quer dizer que a coexistência tenha sido sempre pacífica, como atestam inúmeras revoltas indígenas ocorridas ao longo da história boliviana. Na medida em que o Estado se tornava menos dependente da arrecadação do Tributo Indígena com o desenvolvimento dos enclaves mineiros e a alta nas cotações internacionais dessa commodity, aumentavam também as pressões das haciendas sobre as terras comunais, mas sem que jamais o país tenha conseguido consolidar uma homogeneização modernizadora suficientemente significativa. A sociedade moderna e de valores ocidentais e a economia capitalista inserida no mercado internacional sempre conviveram com comunidades mais ou menos autônomas e tradicionais que funcionavam através de lógicas e estruturas próprias, ao ponto de Luis Tapia afirmar que a "Bolívia não é uma sociedade, mas sim o nome histórico de um país que contém uma diversidade de sociedades em situação de dominação mais ou menos colonial" $(2011,48)$.

A teoria de Gino Germani (1973) sobre a transição latino-americana de sociedades tradicionais a modernas, provavelmente a primeira tentativa autóctone mais robusta e criativa de teorizar esse processo, previa a persistência no tempo de elementos não-modernos, assincronias na transição poderiam vir a constituir uma variedade de modernidades latino-americanas singulares dentro de cujos marcos interpretativos a Bolívia poderia ser considerada um país radicalmente assincrônico, onde persistem inúmeros elementos do contínuo entre os dois polos da escala de transição de Germani. Mas em grande medida, sua perspectiva ainda era bastante baseada metodologicamente em premissas fundamentais das teorias da modernização mainstream já que adotava como parâmetros comparativos uma tipologia dicotômica tradicional/moderno (com este polo equiparado às sociedades industriais europeias) que carregava implícita uma direção final de chegada pré-definida.

Nesse sentido, ainda mais interessante para analisar a situação boliviana parece ser o enfoque teórico proposto por Dipesh Chakrabarty (2000) para a análise histórica dos países de fora do núcleo capitalista avançado. Combatendo a visão evolutiva da história que toma os países avançados 
do Ocidente como paradigmas universais de desenvolvimento para o resto do mundo e trata as diferenças existentes entre o real e esse ideal como mostras de atraso, incompletude e inadequação, Chakrabarty propõe a noção de História 1 (H1) e História 2 (H2) para dar conta do que há de realmente universal entre a história ocidental e do resto do mundo e as particularidades locais. Ele reconhece, seguindo a interpretação marxista, que o capital enquanto relação social, apesar de originado em um local e época específicos, possui de fato tendência à universalização. Em sua expansão ao largo do globo (H1), entretanto, o capital se depara com outras lógicas de funcionamento pré-existentes $(\mathrm{H} 2)$, algumas das quais operando em lógicas antitéticas, outras mais funcionais e passíveis de amálgama, às quais se sobrepõe e se mescla sem que necessariamente as $\mathrm{H} 2$ sejam completamente subsumidas na $\mathrm{H} 1$.

Isto é, as $\mathrm{H} 2$ nunca são completamente superadas e adequadas aos imperativos funcionais do capitalismo, persistindo através de costumes, crenças e valores que até podem vir a ser aproveitados de uma forma ou de outra pela economia capitalista na produção de valor, mas que não possuem qualquer relação diretamente necessária com a reprodução ampliada do capital. É isto que permite que mesmo em tempos de inegável globalização capitalista alcançando os mais longínquos rincões do planeta não aconteça a homogeneização total de costumes esperada por muitos, mas sim persista uma inescapável diversidade humana. Para Chakrabarty, a diversidade dos modos de ser humano faz com que a História dos grupos humanos seja sempre uma $\mathrm{H} 1$ "modificada constitutivamente, mas de modo desigual, por Histórias 2 mais ou menos poderosas" (70). Acreditar que a humanidade convergirá para um padrão universal homogêneo em sua marcha para o progresso seria uma quimera e julgar as incongruências das histórias realmente existentes com relação a esse "padrão universal" é um erro que costuma acarretar consequências deletérias em termos de ação política ou planejamento econômico.

O processo histórico descrito por Marx como acumulação primitiva do capital teria permitido nos países centrais certa homogeneização ao separar os produtores dos meios de produção e obrigá-los a se integrarem ao mercado com a venda de sua força de trabalho para sobreviver, mas mesmo nesses países a homogeneização nunca é completa, embora possa ser hegemônica. Nos países de capitalismo tardio, especialmente naqueles já densamente povoados e com matrizes civilizatórias distintas e arraigadas, como a Índia de Dipesh Chakrabarty, a heterogeneidade resultante é em consequência muito maior. O mesmo se deu na Bolívia, que embora não tenha densidade populacional sequer comparável também possuía 
matrizes civilizatórias bastante antigas e arraigadas e foi ajudada em seu abigarramento pelo processo colonizador já mencionado acima que as permitiu persistir no tempo, ainda que obviamente alteradas e readaptadas ao longo dele, acarretando importantes consequências sobre o modo como se organizou a ação política no país.

\section{Abigarramento e as (im)possibilidades do Estado-nação}

As consequências de sua formação social abigarrada se fizeram óbvias na vida política boliviana. A tão citada instabilidade do país e suas frequentes crises de hegemonia política, embora envolva elementos de natureza institucional e sociológica "clássicos" como ingerência externa, disputas pelo controle de excedentes econômicos e pretorianianismo de determinados atores sociais, ${ }^{4}$ é possível de certo modo ver raízes mais profundas dessa instabilidade na coabitação de sociedades e civilizações sem uma linguagem mediadora comum que sempre foi a Bolívia. A partir dessa concessão de autonomias de facto durante a colonização que perdurou para além da independência do país, o Estado boliviano teve que ir se construindo não como costuma acontecer, fruto de um processo linear de expansão territorial da soberania de um núcleo pré-existente, mas sim em um lento processo de negociação de limites e fronteiras da legitimidade da ação estatal frente a soberanias locais protoestatais constituídas.

Isso gerou uma situação que o cientista político boliviano George Gray Molina caracteriza como um "Estado com furos". ${ }^{5}$ O Estado boliviano não abdica completamente de exercer sua soberania sobre essas áreas, mas precisa constantemente renegociar os limites de sua ação e "se engajar em uma forma indireta de mando que envolve múltiplos agentes e parceiros locais" (Gray Molina 112) que funcionam em muitos casos como verdadeiros protoestados sob a forma de comunidades indígenas, caudilhos locais, sindicatos etc. Ele qualifica essa característica como uma "força da fraqueza" do Estado boliviano, pois ao mesmo tempo em que foi responsável por boa parte de seu caráter histórico convulsivo, dotou-lhe de flexibilidade suficiente

\footnotetext{
${ }^{4}$ Ver, por exemplo, o estudo de Jean-Pierre Lavaud (1998) sobre a instabilidade política boliviana entre a Revolução de 52 e os anos 1980.

5 "State with holes", no original em inglês.
} 
para evitar que essa diversidade resultasse em balcanização. O grande problema do "modelo" sempre foram os casos de conflitos entre mais de uma instância local devido à ausência de uma soberania central mais consolidada capaz de servir como mediação legitimamente reconhecida.

Essa situação institucional levanta analogias interessantes com o que Partha Chatterjee (2008) caracteriza como "sociedade política": grupos por fora da sociedade civil liberal, mas com os quais o Estado necessita se engajar em suas políticas públicas e para isso tem de recorrer a "jeitinhos" e negociações ad hoc. Com a difusão dos princípios de soberania popular a praticamente todos os Estados modernos e com a expansão de seus escopos e alcances em termos de obrigações e políticas públicas, fica inviável não atender de alguma maneira às necessidades mesmo de grupos formalmente em situação de ilegalidade. E como estão fora da lei, tampouco podem ser atendidos através de políticas (policies) públicas universais, mas somente através de ações negociadas por ação política (politics). Aquilo que se convencionou tratar como "sociedade civil" restringe-se a uma esfera pública limitada, frequentemente dominada por indivíduos das classes médias e altas, e definida pelos limites de legitimidade estabelecidos pelo Estado.

Como Michael Neocosmos (2009) chama atenção partindo de um resgate das teorizações originais gramscianas acerca do tema, a sociedade civil não é as organizações e indivíduos que nela atuam, mas sim o espaço mesmo onde se dá essa atuação. E ao contrário do modo como abordam o tema a maioria dos analistas e teóricos de matriz liberal, esse espaço não é um reino da liberdade absoluta, mas sim uma arena cujas regras e limites são definidos pelo próprio Estado e que, portanto, não pode comportar grupos e organizações com interesses conflitantes, como, por exemplo, grupos revolucionários ou de objetivos mais radicais. Essa é a razão, por exemplo, pela qual Luis Tapia (2011) considera que muitos movimentos sociais não são integrantes plenos da sociedade civil, como costumam ser comumente tratados, mas sim formas de organização política que surgem atravessando a mesma e pugnando por reformas que, quando acatadas, modificam as próprias regras do jogo dessa sociedade civil, alterando-a substantivamente, "estranhos nos portões" na definição de Tarrow (2012) permanentemente redefinindo seus limites. No caso boliviano, segundo Tapia (2011), há que se considerar além do mais a existência de movimentos que, mais do que "sociais", são movimentos "societais", já que buscam fazer valer como legítimas outras lógicas de sociedade e matrizes civilizatórias para além da liberal crioula, como no caso das comunidades originárias remanescentes em luta pela superação do forte colonialismo interno (ver, por exemplo, González Casanova) do país. 
Assim, embora Chatterjee utilize esse debate acerca das sociedades políticas/civis para julgar o modo como por necessidade se constroem políticas públicas na Índia (e deixando implícito que o mesmo deva ocorrer em boa parte dos países periféricos), é possível extrapolar um pouco a noção no caso boliviano para além das políticas públicas (onde também se dá o fenômeno), em direção à própria soberania mesma do Estado e sua legitimidade para impor a ordem em todo seu território. Nessa superposição abigarrada através da qual se originou o Estado boliviano, mesmo quando muitas vezes este negava legal e oficialmente a legitimidade de autoridades locais desses movimentos societais como caciques e kurakas comunitários, os governantes se viam forçados a certo reconhecimento de facto dos mesmos como intermediários de forma a garantir algum alcance estatal sobre regiões longínquas.

Com o advento do capitalismo e sua acumulação primitiva que buscou dissolver os laços comunais entre as pessoas e a homogeneizar a todos através do mercado, uma saída para a questão da legitimidade da soberania foi atrelar o Estado à Nação. Uma "comunidade imaginada" (Anderson), a nação pôde servir como poderosa cola a unir os governados sob o Estadonação, mas invariavelmente com a exigência de uma homogeneização prévia entre eles. $O$ ideal da nação, embora nunca atingido totalmente, pressupõe certa homogeneidade entre os nacionais em termos de etnia, cultura, língua, religião etc. Quanto mais heterogêneo, mais difícil seu papel coesivo e o risco de emergirem protonacionalismos internos buscando a secessão e a conformação de um novo Estado-nação "próprio", embora este não seja um desdobramento necessário. A ausência de homogeneidade étnica/cultural sempre pode, ao menos em tese, ser compensada pela adoção de um nacionalismo cívico (Habermas; ver também Germani 104), que unifique o corpus de habitantes através da homogeneização de direitos e deveres dos cidadãos livres, mas como vimos isto tampouco foi o caso no país.

A Bolívia pós-independência excluía completamente a maioria absoluta de seus habitantes, a grande massa indígena e camponesa, não apenas do horizonte de "camaradagem horizontal" de sua comunidade imaginada , mas também de qualquer cidadania que pudesse compensá-la. René Zavaleta (2008) costumava dizer que o país possuía um Estado aparente, sem correspondência real com a nação sobre a qual seria responsável e atribuía a essa característica boa parte da explicação pela recorrente tragédia de perda de território para os países vizinhos. 
A partir do fiasco militar da Guerra do Chaco (1932-35), em que o país perdeu a região do Chaco Boreal após sangrento conflito com o Paraguai, no entanto, a questão passou à linha de frente da política no país. O Chaco é considerado pela historiografia boliviana como um "encontro com a nação", onde intelectuais e setores da classe média urbana tiveram pela primeira vez contato com habitantes dos rincões do país, incluindo muitos indígenas, no fronte de guerra. Ao voltarem para casa ao final do conflito, muitos fervilhavam de novas ideias e visões acerca do país e suas injustiças e a reimaginação da nação boliviana com a inclusão do povo que a compunha foi um ponto fulcral dos novos grupos e projetos políticos que surgiram. Esse fenômeno, da tentativa de construção do "povo" como ator político fundamental e vinculação das massas ao Estado, tão difundido em diferentes variações locais ao largo da América Latina como resposta à crise de dominação oligárquica (Calderón e Jelin), passou a pautar a política no país e atingiria seu ponto máximo com a Revolução de 1952.

Ápice do nacional-popular na Bolívia, a revolução buscou resolver a questão nacional do país adotando uma ideologia de mestiçagem e uma política de modernização capitalista que lograsse a homogeneização pelo mercado requerida para a comunidade nacional. O governo capitaneado pelo Movimento Nacionalista Revolucionário (MNR) nacionalizou as minas, distribuiu terras e tentou promover o desenvolvimento de um setor capitalista agroindustrial no Oriente do país. Concedeu a cidadania universal através do sufrágio e utilizou-se de sua reforma agrária para tentar integrar os índios ao mercado através da concessão de títulos individuais, transformando-os em camponeses livres. Expandiu como nunca até então os alcances e a legitimidade do Estado, mas ainda assim não foi capaz de estruturar um Estado-nação funcional e por isso foi considerada uma "revolução incompleta" (Malloy).

Mas por que fracassou? Para Ximena Soruco, um dos problemas fundamentais é que a ideologia da mestiçagem promovida pelo MNR não superava de fato a lógica de racialização da sociedade implementada pela colonização espanhola. Negavam-se os polos indígena/crioulo, mas propunha-se o mestiço, uma nova raça, como superior, mantendo-se intacta a lógica intrínseca (Soruco Sologuren 57-58). Como a mestiçagem biológica é no país um fato fenotípico dado, o pressuposto da homogeneização promovida pela revolução seria, na verdade, a dissolução dos laços comunais, erroneamente equiparados ao feudalismo, e a subsunção de todos pelo mercado, convertendo a todos os bolivianos em cidadãos integrados a uma sociedade civil sob as regras da cultura dominante: 
[...] el proyecto nacional de 1952, pese a que era más igualitario y no negaba al sector popular, identificado como mestizo y campesino, no contuvo la violencia cotidiana y sistémica de la colonialidad: los indígenas debían dejar la forma comunitaria, convertirse en campesinos libres (la dotación de títulos individuales en la Reforma Agraria de 1953), y si migraban debían blanquearse, es decir, aprender castellano, ir al cuartel, a la escuela, votar, hacerse asalariados, consumidores y ciudadanos, debían hacerse individuos aislados de cualquier lazo comunal, es decir, asumir la subjetividad occidental (Soruco Sologuren 50).

Mas a Bolívia era então um país pobre inserido no sistema-mundo capitalista de forma subordinada e dependente, de modo que o crescimento econômico capaz de gerar excedentes suficientes para um desenvolvimento capitalista autônomo e a integração produtiva dos cidadãos inexistia. Os indígenas convertidos em camponeses permaneceram prisioneiros de uma agricultura rudimentar de subsistência e os que migraram às cidades dificilmente conseguiram se incorporar ao parco mercado de trabalho existente fora das minas, engrossando o subemprego, gerando fenômenos como a cidade de El Alto e mantendo-se muitas vezes em um meio caminho entre a atomização na grande cidade e laços persistentes com sua origem rural e comunitária.

O admirável mundo novo prometido não chega, os indígenas e camponeses que eram a parcela mais pobre da população continuam sendo-o mesmo que em novos papéis (empregadas domésticas, vendedores ambulantes, motoristas de vans do transporte público...) e como a lógica racial permaneceu intacta, o passo seguinte de culpar os indivíduos por sua incapacidade de superar "costumes arcaicos", modernizar-se e se desfazer de vínculos comunais foi imediato. A sociedade boliviana permaneceu abigarrada e colonizada por uma cultura dominante de matriz eurocêntrica. Incapaz de atingir os altos parâmetros da modernidade ocidental tida por experiência universal (Chakrabarty), se vê no espelho como um fracasso.

\section{$\mathrm{O}$ advento da Plurinacionalidade}

Mas se o Estado-nação fracassa e parece impossível no país pela ausência de homogeneização capitalista, então o quê? Ximena Soruco aposta no entroncamento recente entre os horizontes políticos do nacional-popular e do indianismo-comunitário, as duas grandes tradições de movimentos políticos subalternos bolivianos, como condição de possibilidade da 
construção do artefato institucional qualitativamente novo do Estado Plurinacional.

Como visto, o Estado boliviano nasceu de forma elitista imaginando uma nação calcada na exclusão da maioria de sua população por critérios raciais ${ }^{6}$. Entretanto, movimentos contestatórios de base e alguns líderes constituíram um campo político que Zavaleta chamou de nacional-popular e que tiveram por objetivo um horizonte de expansão da nação boliviana englobando todo o povo e democratizando ${ }^{7}$ seu Estado. O fenômeno, também tratado pela academia muitas vezes sob o nome de populismo, ${ }^{8}$ é considerado por Fernando Calderón e Elizabeth Jelin (9-10) como uma criação histórica latinoamericana para o problema político da crise de dominação oligárquica trazida pelos processos de modernização com vistas a combinar a ascensão de incipientes burguesias e setores médios com classes subalternas emergentes que não contavam com canais institucionais adequados para a expressão de seus interesses. Embora a Revolução de 1952 tenha sido o momento de auge dessa tradição política na Bolívia que vinha ganhando momento desde o fiasco da Guerra do Chaco, é possível ver embriões do horizonte nacionalpopular, por exemplo, em governos como os do marechal Andrés de Santa

\footnotetext{
${ }^{6} \mathrm{O}$ critério racial de exclusão raríssimas vezes foi explícito na legislação do país, sendo na verdade exercido através de critérios universais de interpretação da cidadania que, no entanto, tinham um efeito muito concreto de exclusão primordial das massas indígenas. A cidadania fora definida inicialmente como direito ao voto e à participação política, mas restrita por critérios de renda, ausência de servidão ou prestação de trabalhos domésticos e alfabetização, o que obviamente não deixava qualquer margem para a cidadania indígena, os quais eram considerados portadores de (limitados) direitos sociais, mas não políticos e fora do corpus de cidadãos. Com a Constituição de 1938, os requisitos de renda foram excluídos, mantendo-se apenas a exigência de saber ler e escrever, mas o arraigamento da exclusão oficial dos índios da cidadania pode ser observada durante os debates da Assembleia Constituinte que promulgou tal carta magna. A exclusão dos critérios de renda e trabalho não-doméstico já garantiria a cidadania aos indígenas literatos, que embora poucos, existiam por esse critério universal de definição. Entretanto, alguns membros da Constituinte chegaram a propor artigos -não aprovados-garantindo a extensão da cidadania aos índios e discutindo os critérios educativos específicos que lhes poderiam garantir o direito ao voto, e sequer foi considerado por qualquer dos representantes, defensores ou contrários à medida, que a mesma seria redundante. "Este silêncio confirma um status quo oculto: a indianidade era tida como condição suficiente para a exclusão política” (Gotkowitz 119; sobre o tema, ver também Postero 2007).

${ }^{7}$ Entendido aqui em um sentido lato, de ampliação dos espaços de participação e inclusão social, de "processo permanente e nunca inteiramente acabado de concretização da soberania popular" (Avritzer e Costa 704) e não necessariamente no sentido estrito de conformação de uma democracia eleitoral.

${ }^{8} \mathrm{O}$ qual, hoje em dia, adquiriu uma pesada carga pejorativa tanto em sua utilização nas análises políticas midiáticas, quanto na própria academia. Por essa razão, prefiro evitá-lo em detrimento da utilização de nacional-popular, posto que essa carga pejorativa implícita é pesada o suficiente para ofuscar qualquer valor heurístico que o termo populismo enquanto conceito acadêmica pudesse ainda oferecer.
}

Bolivian Studies Journal /Revista de Estudios Bolivianos

http://bsj.pitt.edu

Vol. 20 • 2014 • doi: 10.5195/bsj.2014.87 • ISSN 1074-2247 (print) • ISSN 2156-5163 (online) 
Cruz (1829-39) e Manuel Isidoro Belzú (1848-55) ou nas "republiquetas" préindependência. ${ }^{10}$

Mas além do nacional-popular, o status quo excludente do Estado boliviano também foi desafiado pela tradição indígena-comunitária que após a conquista e colonização espanhola teve na defesa de autonomia de suas terras comunitárias o elemento nuclear de sua ação política. Com um repertório de ações (McAdam, Tarrow e Tilly) alternando estratégias de confrontação com ações legalistas de defesa das terras baseando-se em títulos concedidos pela coroa espanhola e decretos republicanos, engajandose com o Estado em busca de direitos e políticas públicas ou buscando isolamento e distância do mesmo, o movimento indígena-comunitário forjou uma memória de lutas que passou a ser ativamente recuperado e mobilizado por movimentos como o Katarismo. ${ }^{11}$ Apesar de frequentemente considerarse que até meados do século XX os movimentos camponeses consistiram principalmente de explosões localizadas de sublevação com caráter prépolítico por carecer de objetivos explícitos e racionalmente concebidos (Quijano), a historiografia boliviana recente tem mostrado que, ao menos no país, o caráter eminentemente político dos mesmos data de muito antes. ${ }^{12}$

\footnotetext{
${ }^{9}$ Em sua "enciclopédia" sobre a presidência boliviana, o historiador e ex-presidente Carlos Mesa aponta a existência no país de certo senso comum douto que divide dicotomicamente os diversos presidentes bolivianos entre um grupo de presidentes liberal-oligárquicos e outro de nacionalistas (Mesa Gisbert 97). No primeiro grupo, estariam aqueles associados a valores europeus e ideias de progresso através do livre mercado, enquanto no segundo, aqueles associados à defesa dos recursos naturais, a integração das classes populares e a recuperação do poder do Estado, com os quais é perfeitamente plausível a analogia com o horizonte nacional-popular.

${ }^{10}$ Protoestados de curta duração estabelecidos em partes do território hoje correspondente à Bolívia durante o período das lutas independentistas entre 1809 e 1822. Algumas delas se notabilizaram por ostentar uma composição social e uma distribuição de direitos de cidadania muito mais amplas e menos excludentes que a República estabelecida com a independência definitiva do reino espanhol. Sobre a influência de sua memória no horizonte nacional-popular, ver Tapia 2011.

11 Movimento político-cultural indianista de origem aimará iniciado na década de 1970 que buscava a revalorização da cultura e identidade indígena subsumida na identidade camponesa como política oficial do Estado pós-1952. O nome katarismo é uma referência ao aimará Tupaj Katari, líder de uma importante revolta anticolonial entre 1780-81. Deu origem a diversos grupos e partidos políticos de importâncias variadas e teve papel fundamental na reconstrução da identidade indígena como fator político na Bolívia. Ver Guimarães 2010.

12 Ressalte-se que o próprio Aníbal Quijano, escrevendo em 1967, reconhece a deficiência de registros historiográficos mais fortes que pudessem embasar uma análise mais profunda dos movimentos camponeses latino-americanos, o que poderia explicar em parte pela insuficiência de dados essa sua classificação dos mesmos como pré-políticos em sua maioria até pelo menos os anos 1930. No caso boliviano que aqui interessa, de fato, muito da compreensão do caráter político e dos projetos dos
} 
É verdade que os movimentos camponeses-indígenas bolivianos em grande medida apresentam fortes traços do que Quijano define como "movimentos racistas" por seu caráter étnico ou elementos e estruturas tradicionais de mobilização. Contudo, isto não elimina seu caráter político e racional, posto que contaram em muitos casos com programas políticos complexos e elaborados e alcances para além do meramente regional. Já na grande sublevação pan-andina de Túpac Amaru, Tomás Katari e Tupaj Katari de fins do século XVIII, é possível perceber claros objetivos políticos concebidos como resposta à situação de opressão sofrida. Variando conforme a região que nucleava o conflito e os desenvolvimentos internos nas fases da insurgência, Sinclair Thomson (2002) aponta como "facetas da imaginação política indígena" da época projetos que iam da autonomia relativa local com lealdade formal ao rei espanhol à independência nacional em um projeto em aliança com mestiços e crioulos leais. Após fracassos dos primeiros projetos devido, entre outros motivos, a deserções e traições dos aliados não-índios, é verdade que na fase mais radical conduzida por Tupaj Katari em La Paz a insurgência assumiu contornos fortes de antagonismo racial, mas o mesmo não se deveu a um caráter irracional ou pré-político. Pelo contrário, foi fruto de uma deliberação racional e de um projeto político explicitamente enunciado, definido frente aos insucessos das alternativas previamente ensaiadas. Da mesma maneira, também o exército indígena liderado por Pablo Zárate "Willka" mais de cem anos depois durante a Guerra Federal de 1899 possuiu uma organização espacialmente abrangente e dotada de um projeto político claro de recuperação de terras comunitárias e autonomia local ameaçadas pelo progressivo cercamento pelas grandes haciendas. Ele percebeu nas contradições entre os partidos Liberal e Conservador uma possibilidade de efetivar uma aliança política em seu favor com o primeiro,

movimentos indígena-camponeses deve bastante ao seminal ensaio "Oprimidos, mas não vencidos" de Silvia Rivera (1987) e dos estudos publicados pelo grupo Taller de Historia Oral Andina (THOA) da Universidad Mayor de San Andrés, La Paz, que inspiraram muitos historiadores mesmo de fora da Bolívia (por exemplo, Gotkowitz; Hylton \& Thomson 2007; Thomson 2002). Entretanto, é impossível não deixar de perceber nessa análise de Quijano um considerável evolucionismo (Calderón e Jelin 20) e traços do "eurocentrismo cognitivo" denunciado por Chakrabarty (2000) quando ele faz o corte entre os movimentos pré e plenamente políticos no campo a partir da adoção de formas "modernas" de mobilização como o sindicato em detrimento das estruturas étnicas tradicionais de mando. Já muitos dos movimentos indígenacamponeses bolivianos dos séculos XIX e XX como os de hoje não deixavam de ser políticos e modernos pelo apelo a elementos étnicos ou tradicionais, mas o eram às vezes precisamente por isso. Como mostra Alice Soares Guimarães (2010) em sua tese sobre a reemergência das identidades étnicas na Bolívia contemporânea, o apelo às identidades étnicas hoje é uma resposta moderna aos desafios colocados pela atual fase da modernidade e é possível observar em alguns dos movimentos mais antigos estratégias análogas para enfrentar racionalmente os desafios que eram impostos pelo seu tempo.

Bolivian Studies Journal /Revista de Estudios Bolivianos

http://bsj.pitt.edu

Vol. 20 • 2014 • doi: 10.5195/bsj.2014.87 • ISSN 1074-2247 (print) • ISSN 2156-5163 (online) 
mas que foi posteriormente traída pelos liberais após sua vitória sobre os conservadores. ${ }^{13}$

E mesmo com a memória dos fracassos nas tentativas de aliança interracial viva em muitas comunidades, isto não implicou em uma reversão a estratégias "racistas" pré-modernas ou coisa do tipo entre os movimentos que se rearticulavam para defender suas terras frente ao crescente assédio devido à valorização comercial das mesmas pela chegada do nascente sistema ferroviário boliviano. Ainda que mantendo a valorização de elementos étnicos e estruturas tradicionais de organização política, o chamado movimento dos "caciques apoderados" foi capaz de organizar um movimento político de alcance nacional iniciado em 1914 na defesa de seus interesses concretos. Os caciques apoderados exploraram criativa e instrumentalmente as brechas legais e eventuais divisões intraelites, aliando-se taticamente em alguns casos com setores urbanos simpáticos em busca do reconhecimento da validade de títulos de posse fundiária de origem colonial ou republicana e da legitimidade de sua autoridade como intermediários entre o Estado central e as comunidades. Apesar de ter perdido um pouco do ímpeto inicial após a desestruturação social trazida pela Guerra do Chaco, muitas de suas estruturas organizativas e redes prévias foram utilizadas na criação dos nascentes sindicatos rurais da década de 1940 e que contribuíram para os desarranjos e tensões no campo boliviano que precederam e de alguma forma influenciaram os destinos da Revolução de 52 (Gotkowitz).

Embora ambas as tradições -a nacional-popular e o indianismocomunitário- tenham surgido e se consolidado principalmente em desafio ao excludente Estado boliviano, como os principais "estranhos nos portões" (Tarrow 2012) a moldar através de suas estratégias de conflito os próprios contornos do mesmo, as relações entre elas nem sempre foram de aliança ou sequer amistosas. As diferenças de perspectiva e objetivos existentes entre as mesmas foram por vezes utilizadas pelas elites em proveito próprio,

\footnotetext{
${ }^{13}$ Aqui, faço referência apenas ao fato de que havia uma ação política orientada por fins racionais, e portanto moderna, ainda que mobilizada em torno de elementos étnicos tradicionais, sem adentrar muito nos contornos específicos do projeto político de Willka sobre os quais ainda pairam certa controvérsia. Os objetivos de recuperação de terras e autonomia local e sua racionalidade política (em contraposição à barbárie irracional que seus ex-aliados liberais tentaram lhe imputar a posteriori do conflito) parecem já amplamente reconhecidos, mas questões sobre até que ponto o líder indígena buscava a criação de uma república indígena paralela, com ou sem a hegemonia desta sobre a república crioula, ou uma maior inclusão dos indígenas em termos de cidadania na república existente são ainda objeto de profunda controvérsia (ver Condarco Morales; Irurozqui; Mendieta).
} 
como no caso do Pacto Militar-Camponês ${ }^{14}$ utilizado pelas ditaduras pós1964 para dividir camponeses (indígenas) e proletariado. Mas não há dúvidas hoje que a memória de suas agendas inconclusas tem sido um importante catalisador das lutas travadas na Bolívia contemporânea (ver Crabtree e Whitehead; Cunha Filho 2009, 2011a; Hylton \& Thomson 2007; Rivera Cusicanqui; Svampa e Stefanoni; Tapia 2011).

Soruco sustenta que a crise do Estado neoliberal e o quinquênio de lutas 2000-2005 geraram uma conjuntura crítica que aproximou movimentos e atores das duas tradições em torno de uma agenda comum que resultou na eleição de Evo Morales, a convocação da Assembleia Constituinte e a promulgação da nova Constituição Política do Estado (nCPE) e a instauração do Estado Plurinacional. Ela defende que o novo texto constitucional possui chaves importantes capazes de permitir um ponto de partida para a superação das impossibilidades do Estado-nação no país.

O ponto de partida seria o de renunciar à lógica homogeneizante do Estado-nação, que não se refere apenas ao "verniz cultural", mas sim também às lógicas econômica e política. Segundo ela, mais além da diversidade cultural em si o que inviabilizou o Estado-nação na Bolívia foi a subsunção ao capital incompleta e a permanência dessa condição abigarrada com suas "multisociedades" (Tapia 2011) operando com instituições e tempos econômicos distintos.

O ponto-chave da nCPE, portanto, não seria o reconhecimento das diferentes etnias, línguas e costumes culturais, afinal de contas este já estava vigente em grande medida desde a reforma constitucional de 1994 que instituiu a Bolívia como multicultural e pluriétnica. Parte importante da opressão sofrida pelos povos indígenas bolivianos radicava, sem dúvida, nessa ausência de reconhecimento a seus símbolos culturais e modos de vida como válidos, posto que essa ausência constituía barreira para a plena realização de suas capacidades. É através do reconhecimento intersubjetivo que os indivíduos ou grupos constituem sua própria identidade (Honneth) e não é à toa, portanto, que os movimentos de resgate da identidade indígena como o Katarismo citado tenham colocado dentre suas principais demandas iniciais a preservação e revalorização das línguas e costumes ancestrais frente ao

\footnotetext{
${ }^{14}$ Pacto assinado entre o ditador René Barrientos e sindicatos camponeses que subordinava os mesmos e suas milícias às Forças Armadas e sua política anticomunista em troca de favores, terras e políticas públicas (Soto). Antes mesmo das ditaduras militares, contudo, a cooptação do movimento camponês e sua contraposição aos sindicatos urbanos radicalizados já havia sido iniciada pelo próprio MNR (Quijano 177178), tendo cabido aos militares uma mera formalização do pacto.
} 
impulso de homogeneização da cultura crioula dominante e que o governo de Evo Morales devote considerável esforço à valorização pública de símbolos da cultura indígena (ver Howard).

Segundo Soruco, contudo, o problema daquele multiculturalismo liberal conquistado é que no fundo ele continuaria funcionando por uma lógica da equivalência de valor onde todos se igualam em última instância enquanto cidadãos da sociedade civil, subsumidos no mercado. Isto é, podem ser diferentes desde que em última instância aceitem ser iguais e se submetam a um mesmo sistema político-econômico.

Com a plurinacionalidade estabelecida no novo texto constitucional, segundo a autora, reconhecem-se plenamente os diferentes modos de ser boliviano, com suas diferentes instituições políticas e práticas sociais sem exigir-Ihes essa homogeneização. Para isso, a nCPE equipara a nação boliviana não a algum padrão qualquer, mas a sua composição pelo povo definido como a "totalidad de los bolivianos y bolivianas, las naciones y pueblos indígena originario campesinos, y las comunidades interculturales y afrobolivianas" (Constitución Política del Estado apud. Soruco Sologuren 126). Assim fazendo-o, a nCPE admitiria as várias maneiras de ser boliviano sem estabelecer hierarquias. Englobaria aqueles sobre os quais os laços comunitários seguem bastante vigentes em toda sua diversidade, mas sem excluir aqueles sobre quem tais laços já foram completamente dissolvidos, os "bolivianos e bolivianas" cidadãos urbanos individualizados na sociedade civil moderna.

Além disso, ao contrário da Constituição anterior, não remete a soberania sobre o território e seus recursos ao Estado, mas ao próprio povo e põe o Estado como administrador delegado dessa soberania. A nCPE reconhece, ademais, a possibilidade de a soberania ser exercida de maneira direta pelo próprio povo em instâncias regionais ou em terras comunitárias a partir de métodos próprios dos usos e costumes locais, o que para Soruco seria um indício de fusão no texto constitucional dos horizontes nacional e comunitário. O Estado central passaria a ser um articulador dos interesses e políticas maiores, que sobrepassam o local e exigem grandes investimentos, como o aproveitamento e industrialização dos recursos naturais, e que são vitais para a garantia do bem estar de todos os cidadãos e comunidades pelos recursos que geram. Mas essa administração seria sempre passível de revogação e reapropriação pelo povo soberano em caso de má utilização e fetichização do poder (Dussel). 


\section{Estado Plurinacional: prática da teoria e teoria da prática}

Ximena Soruco atribui a essa nacionalização do sujeito indígena um dos elementos essenciais das condições de possibilidade do Estado Plurinacional em construção, mas reconhece o risco de exigir demais de um sujeito muitas vezes idealizado em sua "missão histórica". O risco principal nesse caso, para ela, seria o de que os indígenas, uma vez hegemônicos politicamente, repetissem a mesma política nacional crioula (ou mestiça) meramente invertendo os polos dominante/dominado. Com o plurinacional, Soruco acredita, contudo, que se supera esse risco ao se instaurar outra lógica de vinculação do Estado com suas nações através do povo reconhecido em sua pluralidade:

Por eso la definición del pueblo boliviano en el artículo tercero de la constitución reconoce al plebs (pueblos y naciones indígena originario campesinas que han sido excluidas y que constituyen el sujeto nucleador de la demanda de la asamblea constituyente) pero no en identidad; de tal manera, a lo largo del texto constitucional se habla de pueblos y naciones "indígena originario campesinas", articulando la heterogeneidad interna del propio sujeto indígena (comunidades del Oriente que se autodefinen como indígenas, comunidades andinas que se identifican como originarias, ni indígenas ni campesinas, y sindicatos cuya experiencia histórica con la hacienda y con la Revolución de 1952 les permite apelar al término campesinos). De igual manera, este plebs reconoce a otros actores excluidos como las "comunidades interculturales", que son los sindicatos y organizaciones de campesinos que migraron al Oriente y comunidades afrobolivianas, que son minoritarias, pero que también se reconocen. Pero el plebs constituido también reconoce al populus (la comunidad dominante), si bien no definida como mestizos o regiones, sí como bolivianos y bolivianas, mostrando su relacionamiento individual, de sociedad civil (Soruco Sologuren 151).

Isto neutralizaria, segundo ela, o risco de conformação de um novo nacionalismo étnico indígena que, atendendo às mesmas lógicas do nacionalismo crioulo anterior, poderia levar em última instância a uma fragmentação do território boliviano em várias nações independentes. O elemento principal do horizonte indígena-comunitário seria a autonomia da comunidade, não a identidade étnica, e o novo texto constitucional apontaria nesse sentido, nucleando a própria democracia boliviana e sua construção de hegemonia nos princípios de sua própria diferença em linha com o proposto por Laclau e Mouffe (1987) para uma democracia radical. 
Mas passados já mais de três anos desde a promulgação da nCPE e, portanto, da instituição do Estado Plurinacional, até que ponto a prática política do país vem confirmando a teoria proposta?

Analisando a nCPE e sua proposta de plurinacionalidade, Fernando Mayorga (2009) conclui que embora o texto busque dotar o sistema político boliviano de mecanismos advindos da lógica comunitária, em última instância acaba por subordiná-los à uma lógica política liberal de um cidadão, um voto. Apesar de acatar mecanismos como assembleias, cabildos $^{15}$ e consulta prévia às comunidades como instituições legítimas de deliberação, não Ihes concede caráter vinculante, o que poderia permitir passar por cima de suas deliberações. Além disso, embora reconheça a possibilidade de que os povos indígenas originário-camponeses escolham suas autoridades e representantes segundo "usos e costumes", ressalva que tal se dará apenas quando o ato eleitoral não estiver sujeito ao voto único, secreto e universal. E de fato, no caso da escolha dos representantes indígenas eleitos por cotas na Câmara de Deputados tem sido utilizado o sufrágio clássico sem qualquer matização por usos e costumes. Isso, no entanto, não inviabiliza necessariamente o experimento com o Plurinacional na medida em que da mesma forma em que a $\mathrm{H} 1$ nunca suplanta completamente as $\mathrm{H} 2$, estas tampouco se mantêm inalteradas e puras. Assim, é possível argumentar que a lógica de deliberação política via sufrágio direto universal já tenha penetrado o suficiente nas comunidades locais ${ }^{16}$ de modo a ser aceito como o método por excelência de mediação para o nível superior de governo cuja função seria, lembremos, funcionar como árbitro entre os diversos "protoestados" do Estado com furos. Além do quê, é necessário recordar, dentre os vários grupos étnicos e comunidades interétnicas existentes no país inexiste homogeneidade em suas práticas políticas apesar de serem todas "indígenas", 17 de modo que a seleção de qualquer outra forma de organização política para o nível central de governo não seria necessariamente menos impositiva em relação às demais que o princípio democrático ocidental escolhido.

\footnotetext{
${ }^{15}$ Espécie de assembleias abertas convocadas para deliberar sobre assuntos extraordinários.

${ }^{16}$ Para René Zavaleta (2009b), já em 1979 durante a crise na transição pós-ditadura a "forma democracia" dava indícios de ampla penetração nas massas.

${ }^{17}$ Rótulo, aliás, adotado pelos colonizadores espanhóis para homogeneizar uma vasta população de origens étnicas e costumes culturais diversos, composta por aimarás, quéchuas, urus, chipayas, guaranis, moxeños, tsimanes entre muitos outros.
} 
De qualquer forma, sugere que na prática continue havendo, para além da retórica e das intenções, certa hierarquização de lógicas políticas no que tange ao Estado central, embora em âmbitos locais, como os municípios indígenas autônomos, haja uma autonomia mais real, o que pode ser bastante salutar. Em seu estudo sobre os municípios indígenas de Bolívia e Equador, Donna Lee Van Cott (2008) sugere a existência de efeitos benéficos à democracia local na adoção de algumas práticas e valores ancestrais nos municípios estudados, matizando, contudo, que o caso boliviano era mais limitado devido à maior rigidez institucional prescrita até então pelo marco legal. Sendo assim, é possível esperar agora com as possibilidades outorgadas pela nCPE uma maior democratização local nos municípios indígenas e uma verdadeira adoção de mecanismos próprios de organização do poder, ainda que nada disso atinja o nível central de governo. E mesmo ainda num nível infranacional, mas superior ao municipal, essa hierarquização também se faz presente -e nesse caso mais constrangedora a um horizonte plurinacional pleno- na limitação dos territórios indígenas autônomos a territórios contíguos que não ultrapassem os limites de unidades administrativas já constituídas como municípios e departamentos, conforme estabelecido na Lei de Autonomias de 2010, o que inviabiliza sua constituição em muitos territórios indígenas autônomos em potencial, como no Território Indígena e Parque Nacional Isiboro Sécure (TIPNIS) localizado na fronteira entre os departamentos de Beni e Cochabamba e que, não fosse por isso, teria tudo para se constituir em território autônomo.

Mas ainda mais preocupante em termos do potencial de negação da confluência entre nacional-popular e indianismo em que se apoia Soruco para teorizar sobre o Estado Plurinacional, no entanto, são alguns desdobramentos trazidos pelo recente conflito em torno da construção de uma estrada através do TIPNIS. De todo o imbróglio trazido pelo conflito, ${ }^{18}$ que envolveu uma longa marcha promovida pelos indígenas das terras baixas do Oriente boliviano de Trinidad até La Paz em demanda pela suspensão da construção da estrada, o que cabe ressaltar -além de mais um indício de hierarquização e limitação da autonomia indígena na restrição ao princípio de consulta prévia que em grande medida iniciou o conflito- são indícios de fissuras na unidade promovida pela constituição entre "povos indígenas originário-camponeses".

O termo repetido várias vezes ao longo do texto constitucional sugere uma equivalência de legitimidade enquanto sujeitos políticos entre os vários

${ }^{18}$ Ver Ybarnegaray Ortiz 2011 e Cunha Filho 2011b para uma descrição detalhada do conflito. 
modos de ser indígena na Bolívia, "comunidades del Oriente que se autodefinen como indígenas, comunidades andinas que se identifican como originarias, ni indígenas ni campesinas, y sindicatos cuya experiencia histórica con la hacienda y con la Revolución de 1952 les permite apelar al término campesinos" (Soruco Sologuren 151). Entretanto, no conflito em torno da estrada observou-se claramente uma cisão política entre as organizações desses diversos componentes do mesmo ator. De um lado, apoiando o projeto do governo, a Confederação Sindical Única de Trabalhadores Camponeses da Bolívia (CSUTCB), Federações de Cocaleiros do Trópico de Cochabamba, Federação Nacional de Mulheres Camponesas Bartolina Sisa e Confederação Sindical de Comunidades Interculturais da Bolívia (CSICB). Do outro, a Confederação dos Povos Indígenas do Oriente Boliviano (CIDOB) e Confederação Nacional de Ayllus e Marqas do Qollasuyu (Conamaq).

Embora sugira um afastamento entre elementos do nacional-popular e aqueles mais associados ao indianismo-comunitário, ${ }^{19}$ a característica mais importante do conflito na verdade parece ser certa disputa pela definição dos "indígenas legítimos", o que poderia provocar justamente o nacionalismo indígena de polos invertidos apontado por Soruco como risco ao plurinacional. Durante o conflito foram frequentes as acusações por parte da CIDOB de que os que apoiavam a construção da estrada não seriam indígenas de verdade e esta continua a ser a linha com relação ao Conselho Indígena do Sul (Conisur), grupo indígena não afiliado à CIDOB e habitante do TIPNIS que iniciou em dezembro uma marcha própria rumo a La Paz em demanda da retomada da construção da estrada, suspensa após a marcha da CIDOB. A estratégia de questionar a legitimidade da identidade indígena de seus adversários diretos em torno da construção da estrada através do TIPNIS pode ser apenas um recurso passageiro adotado de forma transitória diante de um embate concreto, uma espécie de jogo sujo visando ganhos imediatos a ser abandonada em seguida. Mas mesmo que o seja, não deixa de ser preocupante em face de possíveis antagonismos mais duradouros que poderá vir a gerar entre os diversos atores, queimando entre eles pontes que até aqui os uniram e dificultando a construção e manutenção de um bloco histórico hegemônico.

${ }^{19}$ Ver Rossell 2012. 
Como aponta Robert Albro (2010), em grande medida devido ao papel dos Kataristas, que se constituíram no movimento indianista ${ }^{20}$ pioneiro e até hoje o de maior alcance no país, o "ser indígena" na Bolívia é frequentemente equacionado com o "ser Aimará" em termos de seus traços definidores. A partir da primeira marcha dos povos indígenas do Oriente e a fundação do CIDOB, dezenas de etnias minoritárias passaram a se organizar politicamente e, ao menos no plano discursivo, atenuaram esse "Aimará-centrismo". Mas a forma como os povos indígenas fazem política a partir de seus valores ancestrais continua a ser tratada em grande medida de uma forma bastante idealizada, como se representassem ainda $\mathrm{H} 2$ puras e onde qualquer traço negativo em um político indígena é atribuído a influências individualistas e consumistas da sociedade ocidental, isto é, a sua perda de identificação com o indianismo "legítimo". Como mostra Alice Guimarães (2010), essa busca por uma essência pura e imutável equivale a negar a própria historicidade dos povos indígenas, a colocá-los como sujeitos pré-políticos. Albro acredita que mesmo a figura dos "povos indígenas originário-camponeses" utilizada pela nCPE para reconhecer direitos coletivos comunitários de um ator unificado em sua diversidade acaba deixando descobertos a inúmeros indígenas urbanizados (cujos números são cada vez maiores) cujas práticas políticas diferem desse ator, mas nem por isso seriam menos indígenas ou deixam de fazer referências concretas a costumes e identidades ancestrais. ${ }^{21}$

Essa discrepância entre o texto constitucional e a realidade concreta da complexidade do ser indígena se mantém também, por exemplo, na seção sobre as diferentes formas de organização econômica do país, na qual se reconhece a economia comunitária, embora em definições um tanto quanto imprecisas (Wanderley). Em muitos sentidos, apesar da noção de abigarramento com que se descreve à Bolívia implicar uma grande complexidade social e interpenetrações em variados graus das distintas civilizações e grupos sociais que compõem o país, muitas vezes os discursos e práticas políticas acabam tratando-a como se houvesse uma divisão dicotômica entre indígena e não indígena, ou entre moderno e comunitário, quando se sabe já há bastante tempo a partir de estudos empíricos

\footnotetext{
${ }^{20} \mathrm{O}$ indianismo se define como um movimento político-cultural de resgate étnico e afirmação política feito eminentemente por atores indígenas, em comparação com o indigenismo, que buscava denunciar a opressão indígena e buscar caminhos para sua inclusão na sociedade a partir de uma lógica eminentemente crioulo-mestiça (ver Bengoa; Favre).

${ }^{21}$ Ver também Stefanoni 2010, 2011 para uma discussão sobre as mutações do "ser indígena" a partir da urbanização e de influências como o evangelismo pentecostal e possíveis incongruências com o ator constitucionalmente reconhecido dos "povos indígena-originário-camponeses".
} 
importantes e consolidados que essa não é a realidade concreta. Herbert Klein (1993) já mostrara o quanto alguns ayllus estavam bem inseridos nas dinâmicas comerciais já no século XIX e ao contrário do que o senso comum a respeito poderia supor, essa inserção mercantil fortaleceu muito mais do que enfraqueceu a manutenção de estruturas comunais e tradicionais étnicas (ver também Ferreira; Saignes), embora é certo que tenham em alguns casos gerado certas tensões a partir das diferenciações e estratificação sociais internas com ela trazidas. E no entanto, na mencionada seção constitucional (bem como no Plano Nacional de Desenvolvimento) a economia comunitária é apresentada por vezes como se fosse uma forma de organização econômica completamente distinta da mercantil capitalista (como se fosse uma $\mathrm{H} 2$ pura e não "contaminada") e mesmo contraposta a esta, como um possível embrião de uma forma de organização econômica completamente nova e que poderia vir a superar a capitalista geral (ver Wanderley).

De qualquer maneira, como lembra a própria Ximena Soruco, a construção em curso do Estado Plurinacional é algo que vem se tentando na prática, sem planos pré-concebidos e, parafraseando o poeta António Machado, "fazendo o caminho ao caminhar". É possível que por esses motivos ou outros o experimento venha a fracassar ou pode ser que as contradições em curso se revelem, como defende o sociólogo e vicepresidente Álvaro García Linera (2011), como "tensões criativas do processo de mudanças", contradições pontuais inevitáveis trazidas pelas demandas de interesse imediato dos diferentes movimentos que compõem a base social do governo, em contraposição às contradições antagônicas estruturais que surgiram na experiência histórica dos movimentos nacional-populares latinoamericanos após chegarem ao poder. Até aqui, no entanto, o experimento parece bem-sucedido ao menos no que concerne ao aumento da democratização do Estado boliviano no sentido geral proposto por Tilly (2007) de um aumento da responsividade estatal frente a seus cidadãos, da incorporação de redes de confiança e de sua capacidade em implementar efetivamente suas políticas e na abertura completa dos horizontes de participação plena dos indígenas na vida política do país.

Tensões criativas ou destrutivas à parte, a capacidade do Estado em implementar suas políticas e sua legitimidade de mediar acordos do tipo "sociedade política" (Chatterjee) são hoje inegavelmente maiores que há alguns anos, embora, é preciso reconhecer, algo desse aumento possa ser fruto da legitimidade pessoal do próprio presidente Evo Morales. Na medida em que sua popularidade decline pelos desgastes naturais a uma longa 
liderança ou que ele venha a ser sucedido por outros, é possível que o país experimente algum aumento de instabilidade, mas são apenas conjecturas. Até aqui, aparentemente vem sendo bem-sucedido na incorporação de elementos e valores comunitários ao arcabouço institucional estatal -ainda que de forma limitada- e é também possível que a Bolívia pós-Evo possa manter-se nesse mesmo caminho virtuoso. Não de se transformar em uma sociedade "ocidental pura", pois tal aspiração seria uma grande quimera e sua impossível busca a origem de mais problemas, mas de consolidar um modelo próprio de democracia vernacularizada pelos valores comunitários locais (Postero 2010).

Independentemente do sucesso que o modelo tentado venha a ter, no entanto, é interessante notar o quanto o caso boliviano é ilustrativo dos potenciais e limites de diversas questões centrais ao pensamento crítico contemporâneo. Trata-se de um dos mais explícitos processos de construção estatal (State building) atuais e onde se podem ver claramente os modos através dos quais os movimentos sociais moldam seus contornos, aproveitando-se de janelas de oportunidade política, mas em muitos casos criando dinamicamente essas mesmas janelas com sua ação (Tarrow 1994, 2012) e pautando os desafios que esse Estado tenta superar a partir da agenda construída por esses mesmos movimentos. Se é verdade que em termos netamente institucionais o Estado Plurinacional parece estar bem aquém do que fora propagado por muitos, como um fenômeno radicalmente distinto do Estado-nação do século XIX, em termos simbólicos de (re) imaginação nacional parece pelo menos vir sendo capaz de dar a esse Estado uma cara muito mais inclusiva.

Além disso, é possível notar no caso boliviano a partir do quinquênio 2000-2005 que abriu essa grande janela para a contestação pelos movimentos sociais ao Estado uma retomada do "horizonte totalizante" de ação apontado por Calderón e Jelin (36) como grande perda dos movimentos latino-americanos a partir dos anos 1980 em relação a seus antecessores. Foi justamente a retomada desse horizonte, provavelmente, o que permitiu aos movimentos bolivianos conformarem diante dessa conjuntura favorável um bloco histórico proto-hegemônico capaz de assumir o governo a partir de 2006.

Se em muitos casos ao largo da América Latina os movimentos sociais se retraíram em posturas autonomistas de quase isolamento frente ao Estado, na Bolívia eles miraram na sua retomada e refundação tida como um objetivo pelo menos desde o fim dos anos 1970 pelos movimentos indígenacamponeses (ver Guimarães 2010) que hoje nucleiam o atual bloco histórico 
no poder. Embora, como visto, a demanda de autonomia comunitária tenha sido elemento central nas demandas indígenas ao longo da história boliviana, esta em geral não significou uma aspiração por isolamento, mas sim uma forma especial de relação com o Estado central. E que em geral veio sempre acoplada de demandas por políticas públicas e direitos de corte universalista, ainda que por vezes calcados na criação de instituições e canais específicos em reconhecimento da diversidade e diferença específicos das comunidades frente ao restante do país, como a justiça indígena. Muitos autores, como Raúl Zibechi (2007) e Michael Neocosmos (2009) têm idealizado essa autonomização e isolamento dos movimentos sociais como capazes de gerar a verdadeira mudança e emancipação social almejada e na teoria de Habermas (ver Avritzer e Costa) essa autolimitação dos movimentos em manter-se fora do Estado adquire mesmo caráter de prescrição normativa. Mas é inegável que com todas as suas contradições e problemas, é na Bolívia atual, onde esses "limites" foram deliberadamente desrespeitados, um dos lugares onde esses movimentos mais têm avançado na conquista de suas demandas.

\section{Referências bibliográficas}

ALBRO, Robert. 2010. "Confounding Cultural Citizenship and Constitutional Reform in Bolivia". Latin American Perspectives 37 (3): 71-90.

ANDERSON, Benedict. 2006. Imagined Communities: Reflections on the Origin and Spread of Nationalism. London: Verso.

AVRITZER, Leonardo e Sérgio Costa. 2004. Teoria crítica, democracia e esfera pública: concepções e usos na América Latina. Dados 47.

[http://www.scielo.br/pdf/dados/v47n4/a03v47n4.pdf] acesso em: 23 set. 2014.

BENGOA, José. 2007. La emergencia indígena en América Latina. México DF.: Fondo de Cultura Económica.

CALDERÓN, Fernando e Elizabeth Jelin. 1987. Clases y movimientos sociales en América Latina: perspectivas y realidades. Buenos Aires: CEDES.

CHAKRABARTY, Dipesh. 2000. Provincializing Europe. Postcolonial Thought and Historical Difference. Princeton: Princeton University Press.

CHATTERJEE, Partha. 2008. La nación en tiempo heterogéneo y otros estudios subalternos. Buenos Aires: Siglo XXI. 
CONDARCO MORALES, Ramiro. 2011. Zárate, el "temible" Willka: historia de la rebelión indígena de 1899 en la República de Bolivia. Santa Cruz de la Sierra: Editorial El País.

CRABTREE, John e Laurence Whitehead, orgs. 2008. Unresolved Tensions. Bolivia Past and Present. Pittsburgh: University of Pittsburgh Press.

CUNHA FILHO, Clayton Mendonça. 2011a. "Evo Morales e a construção do novo bloco histórico: entre o nacional-popular e o indigenismo". Oikos 10 (2): 15073.

---. 2011b. "Evo Morales, o conflito do TIPNIS e as dificuldades de articular uma nação". Boletim OPSA 7 (3): 4-8.

---. 2009. Evo Morales e os Horizontes da Hegemonia: Nacional-popular e Indigenismo na Bolivia em perspectiva comparada. Dissertação de Mestrado . IUPERJ, Rio de Janeiro.

[http://www.scribd.com/doc/27740470/Evo-Morales-e-os-Horizontes-daHegemonia-Nacional-popular-e-Indigenismo-na-Bolivia-em-perspectivacomparada] acesso em 23 set. 2014.

DUNKERLEY, James. 1984. Rebellion in the Veins: Political Struggle in Bolivia, 19521982. London: Verso.

DUSSEL, Enrique. 2007. 20 Teses de Política. São Paulo: Expressão Popular.

FAVRE, Henri. 1998. El indigenismo. México DF: FCE.

FERREIRA, Javo. 2010. Comunidad, indigenismo y marxismo. Un debate sobre la cuestión agraria y nacional-indígena en los Andes. El Alto: Ediciones Palabra Obrera.

GARCÍA LINERA, Álvaro. 2011. Las tensiones creativas de la revolución: la quinta fase del proceso de cambio. La Paz: Vicepresidencia del Estado / Presidencia de la Asamblea Legislativa.

GERMANI, Gino. 1973. Política e Sociedade numa Época de Transição. São Paulo: Editora Mestre JOU.

GONZÁLEZ CASANOVA, Pablo. 2007. "Colonialismo Interno (uma redefinição)". A teoria marxista hoje: problemas e perspectivas. Atilio A. Borón, Javier Amadeo, Sabrina González, orgs. Buenos Aires, São Paulo: CLACSO Expressão Popular. 395-419.

GOTKOWITZ, Laura. 2007. A Revolution for Our Rights: Indigenous Struggles for Land and Justice in Bolivia, 1880-1952. Durham, NC.: Duke University Press Books. 
GRAY MOLINA, George. 2008. "State-Society Relations in Bolivia: The Strength of Weakness". Unresolved Tensions. Bolivia Past and Present. John Crabtree and Laurence Whitehead, eds. Pittsburgh: University of Pittsburgh Press. 109-24.

GUIMARÃES, Alice Soares. 2010. A reemergência de identidades étnicas na modernidade: movimentos sociais e estado na Bolívia contemporânea. Dissertaçao de Doutorado. IESP-UERJ, Rio de Janeiro.

GUIMARÃES, César, José Maurício Domingues e Maria Maneiro. 2009. "Bolívia - A História Sem Fim". A Bolívia no Espelho do Futuro. José Maurício Domingues et al, orgs. Belo Horizonte, Rio de Janeiro: EDUFMG ; IUPERJ. 13-26.

HABERMAS, Jürgen. 2000. "Realizações e limites do Estado nacional europeu". Um Mapa da Questão Nacional. Balakrishnan Gopal, org. Rio de Janeiro: Contraponto. 297-310.

HONNETH, Axel. 1996. The Struggle for Recognition: The Moral Grammar of Social Conflicts. Cambridge, USA: The MIT Press.

HOWARD, Rosaleen. 2010. "Language, Signs, and the Performance of Power: The Discursive Struggle over Decolonization in the Bolivia of Evo Morales". Latin American Perspectives 37 (3): 176-194.

HYLTON, Forrest e Sinclair Thomson. 2007. Revolutionary Horizons: Past and Present in Bolivian Politics. London, New York: Verso.

IRUROZQUI, Martha. 2000. "The Sound of the Pututos. Politicisation and Indigenous Rebellions in Bolivia, 1826-1921". Journal of Latin American Studies 32 (1): 85-114.

KLEIN, Herbert S. 1993. Haciendas and Ayllus: Rural Society in the Bolivian Andes in the Eighteenth and Nineteenth Centuries. Stanford: Stanford University Press.

---. 1992. Bolivia: The Evolution of a Multi-Ethnic Society. New York: Oxford University Press.

LACLAU, Ernesto e Chantal Mouffe. 1987. Hegemonía y estrategia socialista: hacia una radicalización de la democracia. Madrid: Siglo XXI.

LAVAUD, Jean Pierre. 1998. El embrollo boliviano: turbulencias sociales y desplazamientos politicos, 1952-1982. Cochabamba: CESU-IFEA-Hisbol.

MALLOY, James M. 1970. Bolivia: the Uncompleted Revolution. Pittsburgh: University of Pittsburgh Press.

MAYORGA, Fernando. 2009. "Ciudadanía multicultural y Estado plurinacional en Bolivia: Los límites de la reforma constitucional". XXI World Congress of Political Science. Santiago: IPSA/AISP. 
McADAM, Doug, Sidney Tarrow e Charles Tilly. 2009. "Para mapear o confronto político". Lua Nova 76: 11-48.

MENDIETA, Pilar. 2010. Entre la alianza y la confrontación: Pablo Zárate Willka y la rebelión indígena de 1899 en Bolivia. La Paz: Plural Editores.

MESA, Carlos de, José de Mesa y Teresa Gisbert. 2008. Historia de Bolivia.

La Paz: Editorial Gisbert.

MESA GISBERT, Carlos de. 2006. Presidentes de Bolivia: entre urnas y fusiles. La Paz: Editorial Gisbert.

NEOCOSMOS, Michael. 2009. "Civil society, citizenship and the politics of the (im)possible: rethinking militancy in Africa today". Interface 1 (2): 263-334.

POSTERO, Nancy. 2010. "The Struggle to Create a Radical Democracy in Bolivia". Latin American Research Review 45, Special Issue: 59-78.

---. 2007. Now We Are Citizens: Indigenous Politics in Postmulticultural Bolivia. Stanford: Stanford University Press.

QUIJANO, Aníbal. 1967. "Los movimientos campesinos contemporáneos en América Latina". Élites y desarrollo en América Latina. Seymour Martin Lipset e Aldo E. Solari, orgs. Buenos Aires: Paidós. 254-307.

RIVERA CUSICANQUI, Silvia. 1987. Oppressed but not defeated: peasant struggles among the Aymara and Qhechwa in Bolivia, 1900-1980. Geneva: UNRISD.

ROSSELL Arce, Pablo. 2012. "2012: ¿el parteaguas del evismo? Bolivia después del conflicto del Tipnis". Nueva Sociedad 237: 4-16.

SAIGNES, Thierry. 1999. "The Colonial Condition in the Quechua-Aymara Heartland (1570-1780)". The Cambridge History of the Native Peoples of the Americas. Frank Salomon e Stuart Schwartz, orgs. Cambridge: Cambridge University Press. V. 3: South America, Part 2. 59-137.

SIVAK, Martin. 2008. Jefazo - retrato íntimo de Evo Morales. Buenos Aires: Debate.

SORUCO SOlOGUREN, Ximena. 2011. Apuntes para un Estado Plurinacional.

La Paz: Vicepresidencia del Estado / Presidencia de la Asamblea Legislativa. (Investigación para el fortalecimiento del Estado boliviano dentro del proceso de cambio).

SOTO, César. 1994. Historia del Pacto Militar Campesino. Cochabamba: CERES.

STEFANONI, Pablo. 2011. "Bolivia hoy: rupturas, inercias y desafíos". Bolivian Studies Journal / Revista de Estudios Bolivianos 18: 23-48.

---. 2010. "Qué hacer con los indios..." Y otros traumas irresueltos de la colonialidad. La Paz: Plural Editores. 
SVAMPA, Maristella e Pablo Stefanoni, orgs. 2007. Bolivia: memoria, insurgencia y movimientos sociales. Buenos Aires: Editorial El Colectivo.

TAPIA, Luis. 2011. Política salvaje. Buenos Aires: Waldhuter Editores.

---. 2002. La producción del conocimiento local: historia y política en la obra de René Zavaleta. La Paz: Muela del Diablo Editores.

TARROW, Sidney. 2012. Strangers at the Gates: Movements and States in Contentious Politics. Cambridge: Cambridge University Press.

---. 1994. Power in Movement: Social Movements and Contentious Politics. Cambridge: Cambridge University Press.

THOMSON, Sinclair. 2002. We Alone Will Rule: Native Andean Politics in the Age of Insurgency. Madison: University of Wisconsin Press.

TILLY, Charles. 2007. Democracy. New York: Cambridge University Press.

VAN COTT, Donna Lee. 2008. Radical Democracy in the Andes. New York: Cambridge University Press.

WANDERLEY, Fernanda. 2011. "Pluralismo económico, mercado y Estado". Descolonización en Bolivia: cuatro ejes para comprender el cambio. Vicepresidencia del Estado Plurinacional de Bolivia. La Paz: Fundación Boliviana para la Democracia Multipartidaria. 237-68.

YBARNEGARAY ORTIZ, Jenny. 2011. "Bolivia: del 'proceso de cambio' a los cambios en el proceso". Bolivian Studies Journal / Revista de Estudios Bolivianos 18: 70-114.

ZAVALETA MERCADO, René. 2009. La autodeterminación de las masas. Bogotá:

Siglo del Hombre Editores / Clacso (Colección Pensamiento Crítico Latinoamericano).

---. 2008. Lo nacional-popular en Bolivia. La Paz: Plural Editores.

ZIBECHI, Raúl. 2007. Autonomías y emancipaciones: América Latina en movimiento. Lima: Universidad Nacional Mayor de San Marcos (Fondo Editorial de la Facultad de Ciencias Sociales), Programa Democracia y Transformación Global.

\footnotetext{
(cc) B BY-NC-ND

ULLS

This work is licensed under a Creative Commons AttributionNoncommercial-No Derivative Works 3.0 United States License.

This journal is published by the University Library System of the University of Pittsburgh as part of its D-Scribe Digital Publishing Program, and is cosponsored by the University of Pittsburgh Press.
} 